\title{
Desenvolvimento de mudas de Araçá (Psidium sp.) cultivada em diferentes substratos e recipientes
}

Psidium sp. é uma espécie frutífera nativa do Brasil ainda pouco estudada que apresenta grande potencial econômico, alimentar, ambiental e farmacêutico. Desta forma, foi objetivado este estudo sobre mudas de araçá desenvolvidas em diferentes substratos e recipientes. As mudas foram cultivadas em casa de vegetação. Os substratos adotados no trabalho foram: comercial Plantmax ${ }^{\circledR}$ (S1); mistura de terra de barranco, vermiculita e areia fina (S2) em proporção 2:1:1 mistura de terra de barranco e areia fina (S3) em proporção 2:1; mistura de terra de barranco, palha de arroz e areia fina (S4) em proporção 2:1:1. Os recipientes utilizados foram: sacos de polietileno de coloração preta de $15 \mathrm{~cm}$ de diâmetro $\times 25 \mathrm{~cm}$ de altura (R1) com capacidade para $4.415 \mathrm{~cm}^{3} ;$ sacos de polietileno de coloração preta com $7 \mathrm{~cm}$ de diâmetro $\times 15 \mathrm{~cm}$ de altura (R2) e capacidade para $576 \mathrm{~cm}^{3}$; e copo plástico (R3) com capacidade para $250 \mathrm{~cm}^{3}$. Como delineamento experimental foi adotado o esquema fatorial duplo $4 \times 3$, utilizou-se o Teste de Fisher para a comparação das médias e os dados foram submetidos ao teste de robustez. $\mathrm{O}$ araçá pode ser cultivado em diferentes substratos e recipientes no primeiro ano de cultivo da muda.

Palavras-chave: Nativa; Cerrado; Substrato.

\section{Development of Araçá seedlings (Psidium sp.) cultivated in different substrates and containers}

Psidium sp. it is a fruit species native to Brazil that has not yet been studied and has great economic, food, environmental and pharmaceutical potential. In this way, this study aimed at araçá seedlings developed in different substrates and containers. The seedlings were grown in a greenhouse. The substrates adopted in the study were: commercial Plantmax ${ }^{\circledR}$ (S1); mixture of ravine soil, vermiculite and fine sand (S2) in a 2: 1: 1 ratio; mixture of ravine soil and fine sand (S3) in a 2: 1 ratio; mixture of ravine soil, rice straw and fine sand (S4) in a 2:1: 1 ratio. The containers used were: black colored polyethylene bags of $15 \mathrm{~cm}$ in diameter $\times 25$ $\mathrm{cm}$ in height (R1) with a capacity of $4,415 \mathrm{~cm}^{3}$; black colored polyethylene bags $7 \mathrm{~cm}$ in diameter $x 15 \mathrm{~cm}$ high (R2) and capacity for $576 \mathrm{~cm}^{3}$; and plastic cup (R3) with a capacity of $250 \mathrm{~cm}^{3}$. As a $4 \times 3$ double factorial scheme, the Fisher Test was used to compare the means and the data were submitted to the robustness test. Araça can be grown in different substrates and containers in the first year of seedling cultivation.

Keywords: Native; Cerrado; Substrate.

Topic: Melhoramento e Recursos Genéticos

Reviewed anonymously in the process of blind peer.
Received: 06/04/2021

Approved: 03/05/2021
Cassio Yan Faleiro Silva (iD

Instituto Federal de Educação Ciência e Tecnologia Goiano, Brasil http://lattes.cnpq.br/4451752878885613

http://orcid.org/0000-0002-0455-4217

cassioyan@hotmail.com

\section{Mariane Martins de Oliveira (iD)}

Instituto Federal de Educação Ciência e Tecnologia Goiano, Brasil http://orcid.org/0000-0002-8707-7507

marianemoliveira.93@gmail.com

\section{Roberth Regis Silva (iD}

Instituto Federal de Educação Ciência e Tecnologia Goiano, Brasil http://lattes.cnpq.br/3759215170027881

http://orcid.org/0000-0001-9522-8515

roberthregis@gmail.com
Jaqueline Lima da Conceição Souza (iD

Escola de Agronomia da Universidade Federal de Goiás, Brasil http://lattes.cnpq.br/0969910887801284

http://orcid.org/0000-0003-1829-2665

jaquelinelima.745@gmail.com

Eli Regina Barboza de Souza (D)

Escola de Agronomia da Universidade Federal de Goiás, Brasil

http://lattes.cnpq.br/7641431808466123

http://orcid.org/0000-0001-6225-6122

eliregina1@gmail.com

Muza Carmo Vieira (iD

Instituto Federal de Educação Ciência e Tecnologia Goiano, Brasil

http://lattes.cnpq.br/3892400622755069

http://orcid.org/0000-0003-1730-9541

mcvmuza@gmail.com

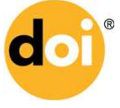

DOI: 10.6008/CBPC2179-6858.2021.005.0005
Referencing this:

SILVA, C. Y. F.; OLIVEIRA, M. M.; SILVA, R. R.; SOUZA, J. L. C.; SOUZA, E. R. B.; VIEIRA, M. C.. Desenvolvimento de mudas de Araçá (Psidium sp.) cultivada em diferentes substratos e recipientes. Revista Ibero Americana de Ciências Ambientais, v.12, n.5, p.49-57, 2021. DOI: http://doi.org/10.6008/CBPC2179-6858.2021.005.0005 


\section{INTRODUÇÃO}

A família das myrtaceaes é uma das maiores famílias botânicas, possui mais de mil espécies e cerca de 140 gêneros, com presença no mundo todo, principalmente em regiões de clima tropical e subtropical (FRANZON et al., 2009). Pertencentes a esta classificação, os araçás, no Brasil ocorrem naturalmente de Pernambuco ao Rio Grande do Sul e podem ser encontrados principalmente na Floresta Ombrófila Densa da faixa litorânea, em matas ciliares, terrenos úmidos e capoeiras (SAUERESSIG, 2014). Os frutos do araçá maduros podem ser brancos, amarelos ou vermelhos, ricos em sacarina e o seu teor de vitamina $\mathrm{C}$ pode chegar a ser quatro vezes maior do que os frutos cítricos. A polpa pode ser consumida in natura ou utilizada na fabricação de refrescos, sorvetes, licores e doces. É suculenta de sabor doce-ácido e agradável (LORENZI et al., 2006; SUGUINO et al., 2006; VIEIRA et al., 2006).

O araçá branco é um arbusto de 1,0 a 1,5 m de altura, que produz frutos de casca amarelada e polpa branca (BEZERRA et al., 2006). Suas folhas são simples, opostas, glabras, coriáceas, pecioladas e suas flores são brancas, hermafroditas e polistêmones, dispõe-se sobre pedúnculos de flores axilares de até 10 mm de comprimento (SAUERESSIG, 2014). Dentre as espécies nativas, o araçá apresenta grande potencial para aproveitamento imediato por parte dos produtores. Algumas seleções já produzem após um ano de plantio, atingindo produção de até $1,0 \mathrm{~kg}$ planta $^{-1}$, enquanto no segundo ano, a produtividade média pode atingir valores superiores a $2,0 \mathrm{~kg}^{\text {planta-1 }}{ }^{-1}$ (TOMAZ et al., 2011).

Segundo Tomaz et al. (2011) a propagação sexuada apresenta melhores resultados quando o objeto é a produção de mudas. Os autores ressaltam que o tratamento das sementes, com imersão em água quente com ácido giberélico, promove um índice de germinação mais homogêneo e emprega maior qualidade ao sistema radicular. Outra questão importante na formação de mudas é saber escolher os substratos e recipientes utilizados. Estes podem influenciar diretamente no seu desenvolvimento, disponibilizando nutrientes, água e espaço para a planta (MENDONÇA et al., 2003).

Trabalhos que aperfeiçoem a utilização de substratos e recipientes para a produção de mudas dessa espécie são relevantes. Desta forma, a necessidade de estudos mais acurados sobre essa planta nativa pode oferecer ao pequeno produtor informações que contribuam para a introdução ao cultivo. Baseado na importância dessa frutífera e nos poucos estudos relacionados à produção de mudas, este trabalho tem como objetivo avaliar o desenvolvimento pela caracterização biométrica na produção de mudas da espécie em diferentes recipientes e substratos.

\section{METODOLOGIA}

Para realização da experimentação, os frutos maduros de Psidium sp. foram coletados em pomares domésticos no município de Ipameri-GO. Após a coleta foram transportados ao laboratório de Biotecnologia LABIOTEC do Instituto Federal Goiano Campus Urutaí-GO, onde passaram por despolpa em água corrente com auxílio de uma peneira.

As sementes despolpadas foram colocadas para secar em papel toalha por 24 horas em temperatura ambiente. Logo depois ficaram por sete dias sendo conservadas em um frasco de vidro 
coberto com chumaço de algodão úmido em ambiente refrigerado com ar corrente de $8^{\circ} \mathrm{C}$. Para a germinação as sementes foram semeadas em número de duas por célula, em bandeja de isopor de 200 células com o substrato, terra de barranco+areia+Bioplant+10 gramas por litro de fertilizante de liberação lenta (Osmocote), até a completa emergência da plântula (4 a 6 folhas emergidas) para serem transplantadas para outro recipiente.

Após a emergência completa foi realizado o transplante das mudas em diferentes tipos de substratos e recipientes para seu desenvolvimento in vivo, sendo eles: SUBSTRATO S1: substrato comercial Plantmax ${ }^{\circledR}$; SUBSTRATO S2: terra de barranco, vermiculita e areia fina, em proporção 2:1:1; SUBSTRATO S3: terra de barranco e areia fina, em proporção 2:1; SUBSTRATO S4: terra de barranco, palha de arroz e areia fina, em proporção 2:1:1. E os recipientes utilizados foram: RECIPIENTE R1: saco de polietileno na coloração preta com $15 \mathrm{~cm}$ de diâmetro x $25 \mathrm{~cm}$ de altura com $4.415 \mathrm{~cm}^{3}$; RECIPIENTE R2: sacos de polietileno de coloração preta com $7 \mathrm{~cm}$ de diâmetro x $15 \mathrm{~cm}$ de altura com $576 \mathrm{~cm}^{3}$; RECIPIENTE R3: copos plásticos com $250 \mathrm{~cm}^{3}$ de volume.

0 delineamento experimental utilizado foi em esquema fatorial duplo $4 \times 3$. Ao todo foram 12 tratamentos sendo eles: T1: R1+S1; T2: R1+S2; T3 R1+S3; T4: R1+S4; T5: R2+S1; T6: R2+ S2; T7: R2+S3; T8: R2+S4; T9: R3+S1; T10: R3+S2; T11: R3+S3; T12: R3+S4. Os materiais ficaram em casa de vegetação anexa ao LABIOTEC em $50 \%$ de sombreamento com temperatura ambiente de $28 \pm 2^{\circ} \mathrm{C}$ por 303 dias.

Ao final do período de desenvolvimento inicial essas mudas foram submetidas a uma caracterização biométrica para avaliar o número de par de folhas (NPF), o comprimento da parte aérea (CPA), o diâmetro do coleto (DC), a massa fresca total (MFT), a massa da raiz (MR), o comprimento da raiz (CR), o comprimento foliar (CF) e diâmetro foliar (DF). Utilizou-se a metodologia com contagem de três pares de folhas totalmente desenvolvidas e escolhidas ao acaso três repetições de cada tratamento. Foram utilizados como instrumentos de medição um paquímetro digital, uma régua milimetrada e uma balança de precisão (Figura 1).

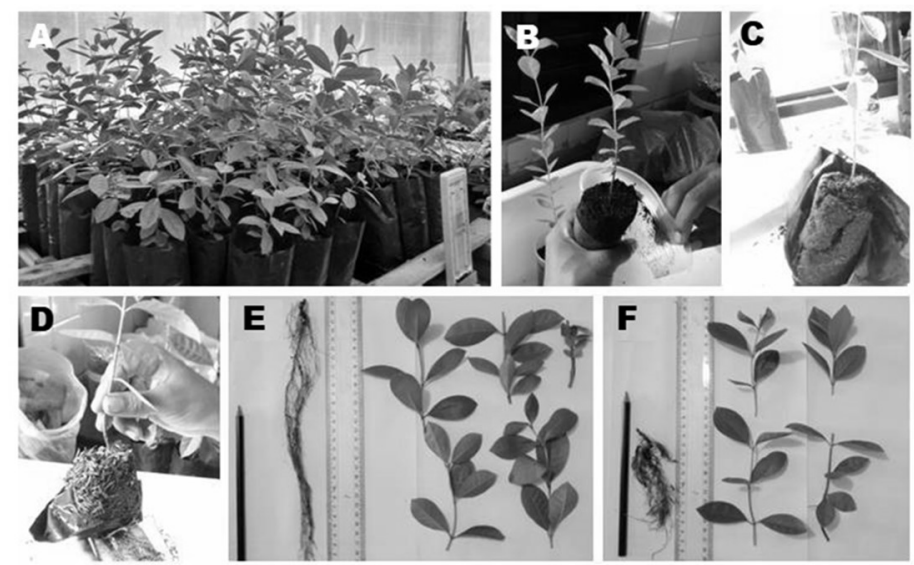

Figura 1: Mudas de araçá 303 dias após semeadura (A); Retirada de saco de polietileno de $576 \mathrm{~m}^{3}$ (B); Em saco de polietileno $4.415 \mathrm{~m}^{3}$ (C); Desenvolvida em substrato $\mathrm{S} 4$ (mistura de terra de barranco, areia fina e palha de arroz) na proporção 2:1:1 (D); Avaliação biométrica de mudas de araçá em diferentes tratamentos (E e F). Laboratório de Biotecnologia do Instituto Federal Goiano - Campus Urutaí-GO, Urutaí-GO, 2019.

O teste de robustez que é a relação da parte aérea pelo diâmetro do coleto (RHDC) foi aferido a partir das médias da altura da parte aérea de cada tratamento dividido pelo valor das médias do diâmetro 
do coleto, segundo Gomes e Paiva (2013). Para a análise estatística, os dados atenderam às pressuposições (normalidade e homocedasticidade), e realizou-se a análise de variância. Identificando-se diferenças significativas $(p<0,05)$ entre os tratamentos, aplicou-se o Teste de Fisher para a comparação das médias. Todas as análises estatísticas foram realizadas com o ambiente R (R Core Team, 2018) de computação.

\section{RESULTADOS E DISCUSSÃO}

Quanto ao teste de robustez (Tabela 1) observa-se que os tratamentos T5, T9, e T12 apresentam os menores valores de RHDC respectivamente em que os tratamentos T5 e T9 possuem o mesmo tipo de substrato sendo ele o substrato Plantmax (S1), já o T9 e o T12 são do mesmo recipiente, o copo (R3). Os tratamentos T1, T2, T3 e T4 (Tabela 1) apresentaram valores mais aproximados dentro de um mesmo recipiente, e mesmo estes possuindo valores maiores pode-se levar em consideração que seriam melhores resultados devido à média do DC ser superior quando comparados aos demais tratamentos.

Tabela 1: Médias dos valores de altura e diâmetro do coleto para os diferentes tratamentos e teste de robustez onde: $\mathrm{H}=$ comprimento da parte aérea expressa em $\mathrm{cm} ; \mathrm{DC}=$ diâmetro do coleto expresso em $\mathrm{mm}$; RHDC = teste de robustez expresso pela divisão da altura pelo diâmetro do coleto. Laboratório de Biotecnologia do Instituto Federal Goiano Campus Urutaí-GO. Urutaí-GO, 2019.

\begin{tabular}{|c|c|c|c|c|c|c|c|c|c|c|c|c|}
\hline & T1 & T2 & T3 & $\mathrm{T} 4$ & T5 & T6 & $\mathrm{T7}$ & T8 & T9 & T10 & T11 & T12 \\
\hline $\mathrm{H}$ & 50,5 & 50,7 & 47,7 & 51,7 & 29,4 & 40,0 & 41,3 & 38,5 & 20,2 & 29,9 & 35,8 & 30,7 \\
\hline DC & 3,2 & 3,3 & 3,0 & 2,9 & 2,8 & 2,4 & 2,7 & 2,5 & 1,7 & 2,2 & 2,1 & 2,4 \\
\hline RHDC & 15,8 & 15,4 & 15,8 & 18,0 & 10,6 & 16,7 & 15,4 & 15,2 & 12,2 & 13,6 & 17,1 & 12,9 \\
\hline
\end{tabular}

Observa-se (Tabela 2) que não houve interação $(p>0,01)$ entre os dois fatores (substrato $x$ recipiente) para comprimento da parte aérea, diâmetro do coleto, comprimento foliar, diâmetro foliar, massa fresca total, número de par de folhas e massa da raiz, exceto o comprimento radicular. 0 recipiente surtiu efeito sobre as variáveis: comprimento da parte aérea, diâmetro do coleto, comprimento foliar, diâmetro foliar, massa fresca total, número de par de folhas e massa da raiz.

Constata-se (Tabela 2) que quando avaliado sozinho, o tipo de recipiente não apresenta diferença significativa na produção de mudas, mas quando o $p$-valor se mostra $<0,05$, sendo realizada a interação entre o fator recipiente mais substrato, isso pode ser influenciado pela diferença significativa que ocorreu ao se analisar a ação do substrato isoladamente.

Tabela 2: Resumo da análise de variância da caracterização biométrica das mudas ao final do experimento para as variáveis: comprimento da parte aérea (CPA), diâmetro do coleto (DC), comprimento radicular (CR), comprimento foliar (CF), diâmetro foliar (DF), massa fresca total (MFT), número de pares de folhas (NPF) e massa da raiz (MR). Laboratório de Biotecnologia do Instituto Federal Goiano Campus Urutaí-GO. Urutaí-GO, 2019.

\begin{tabular}{|c|c|c|c|c|c|c|c|c|c|}
\hline \multirow{2}{*}{ FV } & \multirow{2}{*}{ GL } & \multicolumn{8}{|l|}{ p-Valor } \\
\hline & & CPA & DC & $\mathrm{CR}$ & $\mathrm{CF}$ & DF & MFT & NPF & $\mathrm{MR}$ \\
\hline Substrato & 3 & 0,1965 & 0,9861 & 0,05 & $<0,01$ & $<0,01$ & 0,1377 & 0,2109 & 0,2671 \\
\hline Recipiente & 2 & $<0,01$ & $<0,01$ & 0,1415 & $<0,01$ & $<0,01$ & $<0,01$ & $<0,01$ & $<0,01$ \\
\hline Substrato*Recipiente & 6 & 0,6714 & 0,469 & 0,032 & 0,5867 & 0,4298 & 0,7258 & 0,8302 & 0,2429 \\
\hline CV (\%) & & 22,04 & 18,86 & 26,71 & 16,89 & 17,03 & 39,31 & 15,7 & 38,08 \\
\hline
\end{tabular}

$* *$ P-valor $<0,05$ possui diferença significativa.

O número de folhas, a massa seca da parte aérea e a massa seca total foram semelhantes nas mudas estudadas independentemente do volume do recipiente. Não foi observada diferença significativa entre os tratamentos através do p-valor nos resultados da Tabela 2. Já o teste de Fisher apresentou 
diferença estatística somente para o R3 (copo plástico) quando avaliado o número de pares de folhas e todos os substratos expressaram diferença estatística exceto S1 (Plantmax comercial). A massa fresca total que representa o desenvolvimento completo da muda apresentou diferença estatística apenas para o R3.

É possível notar (Tabela 3) que não houve diferença significativa nos recipientes com o substrato S3 (mistura de terra de barranco e areia fina) para o comprimento da parte aérea, o diâmetro foliar e a massa da raiz. Para o substrato S1 (substrato comercial Plantmax ${ }^{\circledR}$ ), substrato S2 (mistura de terra de barranco, vermiculita e areia fina) e o substrato S4 (mistura de terra de barranco, palha de arroz e areia fina) o recipiente $\mathrm{R} 1 \mathrm{com}$ volume de $4.415 \mathrm{~cm}^{3}$ proporcionou os maiores resultados em todas as variáveis analisadas, sendo estatisticamente iguais ao recipiente $\mathrm{R} 2 \mathrm{com} 576 \mathrm{~cm}^{3}$ para o diâmetro do coleto.

Quando se leva em consideração os recipientes nos diferentes substratos, observa-se que não houve diferença significativa entre os substratos no recipiente R3 (copo plástico) para o diâmetro do coleto, a massa fresca total, o número de par de folhas e a massa da raiz, exceto para o comprimento de parte aérea. No recipiente $\mathrm{R} 1 \mathrm{com} 4.415 \mathrm{~cm}^{3}$ não houve diferença significativa quanto ao comprimento da parte aérea, diâmetro do coleto, diâmetro foliar, massa fresca total, e número de par de folhas. Ainda, não houve diferença significativa quanto ao recipiente $\mathrm{R} 2 \mathrm{com} 576 \mathrm{~cm}^{3}$ para o comprimento da parte aérea, diâmetro do coleto, comprimento da raiz, massa fresca total e massa da raiz.

A partir do teste de Fisher (Tabela 3) é analisado que o DC não apresenta diferença significativa em comparação aos recipientes, já em relação ao substrato o teste mostra uma diferença significativa em todos os tratamentos, exceto o substrato S2 que contém vermiculita. Quanto à massa da raiz o recipiente R1 não apresentou diferença estatística entre os demais na produção de mudas, quando feita a comparação entre os substratos. O S3 também não demonstrou diferença estatística na comparação pelo teste de Fisher.

Mudas de qualidade devem ter idade e tamanho adequado para serem transportadas para o local de plantio definitivo, além de resistirem às condições adversas e apresentarem crescimento satisfatório (GOMES, 2013). Gomes et al. (2002) argumenta que a adoção somente da altura para estimar a qualidade de mudas pode ser utilizada, por apresentar uma boa contribuição relativa ao trabalho, sua medição ser fácil e de se tratar de um método não destrutivo. Neste estudo observou-se que as mudas atenderam ao pressuposto de desenvolvimento nos diferentes recipientes e substratos, quando o objetivo foi à produção de mudas de araçá para a introdução ao cultivo.

Ao se analisar o tamanho de diâmetro do coleto, este caractere quando bem desenvolvido, geralmente está relacionado a um sistema radicular abundante, o que favorece o estabelecimento e o crescimento das plantas em condições de mato-competição (CARGNELUTTI FILHO et al., 2012). Gomes e Paiva (2013), afirmam que o diâmetro do coleto é um dos mais importantes parâmetros para se avaliar o bom desenvolvimento da muda, pois combinado com a altura, diâmetros maiores do coleto proporcionam maior equilíbrio e sustentação para a planta. O que pôde ser observado no presente estudo, uma vez que os valores aferidos na biometria das mudas foram altos, confirmando a hipótese levantada.

Segundo Gomes e Paiva (2013) o RHDC define o quociente de robustez. Ele fornece informações de 
quanto delgada está a muda. Neste índice quanto menor for o seu valor, maior será a capacidade das mudas sobreviverem e se estabelecerem no seu plantio. Ao levar em consideração o poder de matocompetição as plantas com tamanhos maiores podem se tornar mais competitivas em campo, uma vez que as plantas necessitam da luz do sol para se desenvolverem o que acontece com os tratamentos T1, T2, T3 e T4 que em ambiente pós-plantio podem se sobressair em relação às plantas espontâneas do local.

Tabela 3: Comparações de médias das variáveis: comprimento da parte aérea (CPA), diâmetro do coleto (DC), comprimento radicular (CR), diâmetro foliar (DF), massa fresca total (MFT), número de pares de folhas (NPF) e massa da raiz (MR) a partir da caracterização biométrica das mudas. Laboratório de Biotecnologia do Instituto Federal Goiano Campus Urutaí-GO. Urutaí-GO, 2019.

\begin{tabular}{|c|c|c|c|c|}
\hline \multirow{2}{*}{ Variáveis } & \multirow{2}{*}{ Substrato } & \multicolumn{3}{|l|}{ Recipiente } \\
\hline & & $\mathrm{R} 1$ & $\mathrm{R} 2$ & R3 \\
\hline \multirow{4}{*}{ CPA } & S1 & $20,16 \mathrm{bB}$ & $50,5 \mathrm{Aa}$ & $29,43 \mathrm{aB}$ \\
\hline & $\mathrm{S} 2$ & $30,7 \mathrm{abB}$ & $51,7 \mathrm{aA}$ & $38,46 \mathrm{aAB}$ \\
\hline & S3 & 35,83 aA & 47,66 aA & $41,13 \mathrm{aA}$ \\
\hline & S4 & $29,93 \mathrm{abB}$ & 50,66 aA & $40 \mathrm{aAB}$ \\
\hline \multirow{4}{*}{$D C$} & S1 & $1,65 \mathrm{aB}$ & $3,2 \mathrm{aA}$ & 2,78 aA \\
\hline & $\mathrm{S} 2$ & $2,38 \mathrm{aA}$ & $2,88 \mathrm{aA}$ & $2,54 \mathrm{aA}$ \\
\hline & S3 & $2,09 \mathrm{aB}$ & $3,02 \mathrm{aA}$ & $2,69 \mathrm{aAB}$ \\
\hline & S4 & $2,2 \mathrm{aB}$ & $3,29 \mathrm{aA}$ & $2,4 \mathrm{aB}$ \\
\hline \multirow{4}{*}{ CR } & S1 & $23,5 \mathrm{aAB}$ & 27,93 aA & $15,33 \mathrm{aB}$ \\
\hline & S2 & $16,93 \mathrm{abA}$ & $16 \mathrm{bA}$ & 17,33 aA \\
\hline & S3 & $9,66 \mathrm{bB}$ & $20,33 \mathrm{abA}$ & $18,03 \mathrm{aA}$ \\
\hline & S4 & $23 \mathrm{aA}$ & $18,66 \mathrm{bA}$ & 15,66 aA \\
\hline \multirow{4}{*}{ DF } & S1 & $1,83 \mathrm{bB}$ & $3,6 \mathrm{aA}$ & $1,96 \mathrm{bB}$ \\
\hline & S2 & $2,63 a b B$ & $3,6 \mathrm{aA}$ & 3,03 aAB \\
\hline & S3 & $3,1 \mathrm{aA}$ & 3,83 aA & 3,63 aA \\
\hline & S4 & $3,06 \mathrm{aB}$ & 4,33 aA & $3,4 \mathrm{aB}$ \\
\hline \multirow{4}{*}{ MFT } & S1 & $2,71 \mathrm{aB}$ & 14,79 aA & $5,24 \mathrm{aB}$ \\
\hline & S2 & $5,38 \mathrm{aB}$ & $15,62 \mathrm{aA}$ & $10,68 \mathrm{aAB}$ \\
\hline & S3 & $7,26 \mathrm{aB}$ & $15,11 \mathrm{aA}$ & 9,76 aAB \\
\hline & S4 & $7,08 \mathrm{aB}$ & 20,55 aA & $8,74 \mathrm{aB}$ \\
\hline \multirow{4}{*}{ NPF } & S1 & $11,66 \mathrm{aB}$ & $17 \mathrm{aA}$ & $14,66 \mathrm{aAB}$ \\
\hline & S2 & $12 \mathrm{aB}$ & $16 \mathrm{aA}$ & $12,33 \mathrm{abB}$ \\
\hline & S3 & $11,33 \mathrm{aAB}$ & $14,66 \mathrm{aA}$ & $11 \mathrm{bB}$ \\
\hline & S4 & $11 a B$ & 16,33 aA & $11,66 \mathrm{abB}$ \\
\hline \multirow{4}{*}{ MR } & S1 & $0,96 \mathrm{aB}$ & $3,63 \mathrm{bA}$ & $1,61 \mathrm{aB}$ \\
\hline & S2 & $1,3 \mathrm{aB}$ & $3,74 \mathrm{bA}$ & $2,23 \mathrm{aAB}$ \\
\hline & S3 & $1,85 \mathrm{aA}$ & $3,28 \mathrm{bA}$ & 1,93 aA \\
\hline & S4 & $1,59 \mathrm{aB}$ & 5,53 aA & $1,72 \mathrm{aB}$ \\
\hline
\end{tabular}

* Médias seguidas de mesma letra minúscula na coluna e maiúscula na linha não se diferem estatisticamente pelo teste LSD a $5 \%$ de significância.

$\mathrm{Na}$ produção de mudas os recipientes atuam na proteção das raízes e contribuem no melhor manejo dentro do viveiro e transporte seja para lugares mais próximos ou distantes. Recipientes com dimensões maiores podem influenciar na melhor arquitetura das raízes, maior disponibilidade de água e nutrientes (GOMES, 2013). Sabe-se que os maiores problemas em relação à escolha de um recipiente para a produção de mudas é o enovelamento da raiz e a disponibilidade de nutrientes, uma vez que quanto menor o recipiente maior a probabilidade de enovelamento e menor a disponibilidade de nutrientes por conta da baixa quantidade de solo para a sustentação da planta. Deste modo, as mudas de araçá podem ser produzidas em diferentes dimensões de recipientes, desde que observados o tempo de permanência.

Em estudos Cunha et al. (2005) constataram que as dimensões dos recipientes influenciaram o comprimento da raiz principal para a espécie Tabebuia impetiginosa (Mart. Ex D.C) Standl. O recipiente de saco plástico (15×25) utilizado na produção das mudas de araçá neste estudo foi ideal para a produção das mudas, pois os tratamentos em que foram utilizados apresentaram maiores massas e comprimento de 
raízes. Esse fato se deve ao maior espaço para o seu desenvolvimento, diminuindo a frequência de enovelamento, que pode ser um fator limitante na adaptação e desenvolvimento da muda em campo. Ao avaliar o crescimento, produção de fitomassa e qualidade de porta-enxerto de goiabeira 'Crioula' sob estresse salino e doses de adubação nitrogenada, em condições de ambiente protegido Souza et al. (2017) constataram que adubação nitrogenada nas doses de 70 e $100 \%$ de $\mathrm{N}$ recomendada reduziu o efeito da salinidade da água de irrigação sobre a taxa de crescimento relativo do diâmetro do caule de portaenxertos de goiabeira.

Atualmente são desenvolvidos novos materiais para produção de mudas que atuam melhorando na qualidade de raiz. Todavia, esses recipientes podem ser de difícil acesso por possuírem um alto valor de aquisição, se tornando inviável para produtores que não dispõe de maiores investimentos. Recipientes mais acessíveis como os trabalhados no presente estudo, pode ser uma boa opção para quem procura diminuir custos fixos de produção e continuar as atividades do viveiro.

Outra informação que pode se levar em consideração a respeito do tamanho do recipiente é a capacidade de influenciar no número de dias de desenvolvimento da muda. Os recipientes menores reduzem a taxa de crescimento das mudas, implicando aumento do ciclo de produção (CUNHA et al., 2005). Portanto, é preciso levar em consideração o tempo de permanência das mudas nos recipientes. Mudas de araçá podem ser mantidas por até três meses em recipientes menores, sem que isso atrapalhe seu desenvolvimento no campo após o plantio.

Assim como constataram Denner et al. (2007), para as espécies de jabuticabeira (Plinia sp.) os diferentes recipientes não apresentam diferenças significativa quanto ao desenvolvimento de parte aérea. Porém, Ferraz et al. (2011) relatam que recipientes de volume maior proporcionaram as mudas de jatobá, ipê-amarelo e guarucaia maior altura e diâmetro do colo, além de ter conferido maior desenvolvimento da parte aérea e do sistema radicular das plantas, possibilitando uma redução no tempo de produção. Diante disso, é necessário levar em consideração o porte de cada espécie, o tipo de planta e o tempo de permanecia dessas mudas nos recipientes.

Para Cunha et al. (2005), as mudas de ipê-roxo podem ser satisfatoriamente produzidas em sacos de polietileno de $15 \times 32 \mathrm{~cm}$. Os autores argumentam que utilizando o substrato terra de subsolo + compostos orgânicos, é possível ter interação entre o substrato e o recipiente utilizando. Elementos estes de baixo custo, normalmente disponíveis no próprio meio rural.

A principal função do substrato é a sustentação da planta e fornecimento de nutrientes. É composta de uma fase sólida, por partículas minerais e orgânicas, uma líquida, água com nutrientes e uma fase gasosa que é o ar que se encontra em sua porosidade (GOMES, 2013). Portanto, a escolha do substrato é uma das formas de proporcionar a planta condições ideais para o desenvolvimento dos atributos que ela necessita para ser levada ao campo.

Os substratos devem ser constituídos de materiais que permitam o completo desenvolvimento das mudas. Nesse sentido, a utilização de matéria orgânica do tipo de palha de arroz é viável para a germinação de sementes, sendo preferível para o desenvolvimento de mudas a adição de matéria orgânica como 
esterco bovino em conjunto com outros insumos (ARAÚJO, 2011; SOBRINHO, 2011). Já segundo Sobrinho et al. (2010) a adição de esterco bovino ou palha de arroz carbonizada ao solo interferiu negativamente no desenvolvimento das mudas de espécies arbóreas do Cerrado.

Conforme Saidelles et al. (2009) a utilização de diferentes proporções de palha de arroz carbonizada no solo influenciou significativamente nos parâmetros biométricos e índices de qualidade das mudas sendo que para a produção de mudas de tamboril com um adequado padrão de qualidade recomenda-se utilizar 50\% de casca de arroz carbonizada $+50 \%$ de solo. Denner et al. (2007) constataram que a utilização de vermiculita no desenvolvimento de espécies da família Myrtaceae não apresentou vantagem significativa.

O desenvolvimento das mudas, assim como a produção de frutos, depende do manejo adotado. Deve-se sempre levar em consideração o objetivo final do processo a ser empenhado. Assim fatores como, espécies, cultivar, época, clima, solo são relevantes na produção de mudas de qualidade. É importante lembrar que tais fatores sempre devem ser permeados de um bom substrato para cultivo e um recipiente apropriado, além do tempo de permanência da muda no recipiente. Nesse sentido Ferreira et al. (2016) em estudo com desempenho produtivo de amoreira-preta, argumenta que o desempenho produtivo depende de cada cultivar e do sistema de condução adotado.

\section{CONCLUSÕES}

O araçá pode ser cultivado em diferentes tipos de substratos e recipientes por determinado período de tempo. O recipiente R1 (saco de polietileno de coloração preta de $15 \mathrm{~cm}$ de diâmetro x $25 \mathrm{~cm}$ de altura) com capacidade de $4.415 \mathrm{~cm}^{3}$ apresentou os maiores resultados em todas as variáveis analisadas. O recipiente R3 (copo descartável com capacidade para $250 \mathrm{~cm}^{3}$ ) apresentou os maiores resultados quando utilizado o substrato S3 para o comprimento da parte aérea.

\section{REFERÊNCIAS}

ARAÚJO, A. P.; SOBRINHO, S. P.. Germinação e produção de mudas de tamboril (Enterolobium Contortisiliquum (Vell.) Morong) em diferentes substratos. Revista Árvore, v.35, n.3, p.581-588, 2011. DOI: http://doi.org/10.1590/S0100$\underline{67622011000400001}$

BEZERRA, J. E. F.; LEDERMAN, I. E.; SILVA JUNIOR, J. F.; PROENÇA, C. E. B.. Araçá. In VIEIRA, R. F.; COSTA, T. S. A.; SILVA, D. B.; FERREIRA, F. R.; SANO, S. M.. Frutas Nativas da Região Centro-Oeste do Brasil. Brasília: Embrapa Recursos Genéticos e Biotecnologia, 2006.

CARGNELUTTI FILHO, A.; ARAÚJO, M. M.; GASPARIN, E.; ÁVILA, A. L.. Dimensionamento amostral para avaliação de altura e diâmetro de mudas de Cabralea canjerana. Ciência Rural, v.42, n.7, p.1204-1211, 2012. DOI: http://doi.org/10.1590/S0103-84782012000700011

CUNHA, A. O.; ANDRADE, L. A.; BRUNO, R. L. A.; SILVA, J. A. L.; SOUZA, V. C.. Efeitos de substratos e das dimensões dos recipientes na qualidade de mudas de Tabebuia impetiginosa (Mart. Ex D.C.) Standl. Revista Árvore, v.29, n.4, p.507-516, 2005. DOI: http://doi.org/10.1590/S0100-

\section{2}

DENNER, M. A.; CITADIN, I.; FERNANDES, A. A. J.; ASSAMANN, A. P.; MAZARO, S. M.; SASSO, S. A. Z.. Formação de mudas de jabuticabeira (Plinia sp.) em diferentes substratos e tamanhos de recipientes. Revista Brasileira de Fruticultura, v.29, n.1, p.179-182, 2007. DOI: http://doi.org/10.1590/S0100-2945200700010003

FERRAZ, A. V.; ENGEL, V. E.. Efeito do tamanho de tubetes na qualidade de mudas de jatobá (Hymenaea courbaril L. Var. stilbocarpa (Hayne) Lee Et Lang.), ipê-amarelo (Tabebuia chrysotricha (Mart. Ex Dc.) Sandl.) e guarnica (Parapiptadenia rigida (Benth.) Brenan). Revista Árvore, v.35, n.3, p.413-423, 2011. DOI: http://doi.org/10.1590/S0100-67622011000300005

FERREIRA, L. V.; PICOLOTTO, L.; COCCO, C.; FINKENAUER, D.; ANTUNES, L. E. C.. Produção De Amoreira-Preta Sob Diferentes Sistemas De Condução Blackberry Yield On Different Trellis Systems. Ciência Rural, v.46, n.3, p.421-427, 2016. DOI: http://doi.org/10.1590/0103-8478cr20140601

FRANZON, R. C.; CAMPOS, L. Z. O.; PROENÇA, C. E. B.; SILVA 
J. C. S.. Araçás do Gênero Psidium: principais espécies, ocorrência, descrição e usos. Planaltina: Embrapa Cerrados, 2009.

GOMES, J. M.; COUTO, L.; LEITE, H. G.; XAVIER, A.; GARCIA, S. L. R.. Parâmetros na avaliação da qualidade de mudas de Eucalyptus grandis. Revista Árvore, v.26, n.6, p.655-664, 2002. DOI: http://doi.org/10.1590/S0100$\underline{6762200200060000}$

GOMES, J. M.; PAIVA, H. N.. Viveiros florestais. Propagação Sexuada. Viçosa: EdUFV, 2013.

LORENZI; H.; BACHER; L.; LACERDA; M.; SARTORI; S.. Frutas Brasileiras e Exóticas Cultivadas. Nova Odessa: Instituto Plantarum, 2006.

MENDONÇA, V.; ARAÚJO NETO, S. E.; RAMOS, J. D.; PIO, R.; GONTIJO, T. C. A.. Diferentes substratos e recipientes na formação de mudas de mamoeiro 'Sunrise Solo'. Revista Brasileira de Fruticultura, v.25, n.1, p.127-130, 2003. DOI: http://doi.org/10.1590/S0100-29452003000100036

R Core Team. R: a language and environment for statistical computing. R Foundation for Statistical Computing, 2018.

SAIDELLES, F. L. F.; CALDEIRA, M. V. W.; SCHIRMER, W. N.; SPERANDIO, H. V.. Casca de arroz carbonizada como substrato para produção de mudas de tamboril-da-mata e garapeira. Seminário Ciências Agrárias, v.30, n.1, p.11731186, 2009. DOI: http://doi.org/10.5433/1679$\underline{0359.2009 v 30 n 4 S u p 1 p 1173}$
SAUERESSIG, D.. Arvores Nativas: um guia detalhado para identificação de arvores no Brasil. Irati: Plantas do Brasil, 2014.

SOBRINHO, S. P.; LUZ, P. B.; SILVEIRA, T. L. S.; RAMOS, D. T.; NEVES, L. G.; BARELLI, M. A. A.. Substratos na produção de mudas de três espécies arbóreas do cerrado. Revista Brasileira de Ciências Agrárias, v.5, n.2, p.238-243, 2010. DOI: http://doi.org/10.5039/agraria.v5i2a741

SOUZA, L. P.; NOBRE, R. G.; SILVA, E. M.; GHEYI, H. R.; SOARES, L. A.. Produção de porta-enxerto de goiabeira cultivado com águas de diferentes salinidades e doses de nitrogênio. Revista Ciência Agronômica, v.48, n.4, p.596604, 2017 DOI: http://doi.org/10.5935/1806-6690.20170069

SUGUINO, E.; HEIFFIG, L. S.; AGUILA, S. J.; MINAMI, K.. Mirtáceas com frutos comestíveis do Estado de São Paulo: conhecendo algumas plantas. Piracicaba: Escola Superior de Agricultura Luiz de Queiroz, 2006.

TOMAZ, Z. F. P.; GALARÇA, S. P.; LIMA, C. S. M.; BETEMPS, D. L.; GONÇALVES, D. L.; RUFATO, A. R.. Tratamento préemergente em sementes de araçá (Psidium cattleyanum Sabine L.) Revista Brasileira de Agrociência, v.17, n.1, p.6065, 2011. DOI: http://doi.org/10.18539/CAST.V17I1.2032

VIEIRA, R. F.; AGOSTINI-COSTA, T. S.; SILVA, D. B.; SANO, S M.; FERREIRA, F. R.. Frutas nativas da região Centro-Oeste do Brasil. Brasília: Embrapa Recursos Genéticos e Biotecnologia, 2006.

A CBPC - Companhia Brasileira de Produção Científica (CNPJ: 11.221.422/0001-03) detém os direitos materiais desta publicação. Os direitos referem-se à publicação do trabalho em qualquer parte do mundo, incluindo os direitos às renovações, expansões e disseminações da contribuição, bem como outros direitos subsidiários. Todos os trabalhos publicados eletronicamente poderão posteriormente ser publicados em coletâneas impressas sob coordenação da Sustenere Publishing, da Companhia Brasileira de Produção Científica e seus parceiros autorizados. Os (as) autores (as) preservam os direitos autorais, mas não têm permissão para a publicação da contribuição em outro meio, impresso ou digital, em português ou em tradução. 